\title{
Cinema e educação: $O$ uso do filme 'Os delírios de consumo de Becky Bloom' para introduzir o conteúdo de números inteiros
}

\section{Cinema and education: The use of the film 'The Consumer Delusions of Becky Bloom' to introduce the contents of whole numbers}

\author{
Rosângela Silveira da Rosa \\ Diplomada em Matemática e Economia, mestre em Ensino de Ciências e Matemática, docente de matemática na rede Municipal de Ensino de \\ Florianópolis, Santa Catarina. E-mail: rosangelasilveira_31@hotmail.com \\ Mauro José da Rosa \\ Diplomado em Psicologia, mestre em Psicologia, docente na Universidade do Vale do Itajaí - UNIVALI, Itajaí, Santa Catarina. E-mail: \\ maurojr@univali.br
}

Resumo: O presente artigo busca ressaltar a importância da utilização de filmes cinematográficos como elementos facilitadores da Aprendizagem Significativa. Nesta perspectiva, foi realizada uma análise do filme 'Os Delírios de Consumo de Becky Bloom' (2009), para ser apresentado como organizador prévio para a introdução dos Números Inteiros. O filme ora mencionado reporta a situação embaraçosa vivida por uma jovem que não sabia administrar suas finanças e por isso acumula muitas dívidas. Nesse contexto, os débitos foram equiparados a números negativos e os créditos equiparados a números positivos possibilitando também a abordagem do algoritmo da adição desse tipo de número. Os resultados apontam para a importância da utilização de filmes como organizadores prévios para a contextualização de conteúdos matemáticos, visto que estes, fazem parte do cotidiano dos alunos, além de tornar as aulas de Matemática mais coloridas e interessantes aos olhos desses aprendizes.

Palavras-chave: Organizador prévio. Filmes Cinematográficos. Números Inteiros. Ensino de Matemática.

Abstract: This article aims to highlight the importance of the use of cinematographic films as facilitators of Significant Learning. In this perspective, an analysis was made of the film 'The Consumer Delusions of Becky Bloom' (2009), to be presented as a previous organizer for the introduction of the Whole Numbers. The film mentioned above reports the embarrassing situation experienced by a young woman who did not know how to manage her finances and therefore accumulates many debts. In this context, the debts were equated to negative numbers and the credits equated to positive numbers, making it possible to approach the algorithm of adding this type of number. The results point to the importance of the use of films as previous organizers for the contextualization of mathematical contents, since these are part of the students' daily life, besides making Mathematics classes more colorful and interesting in the eyes of these apprentices.

Keywords: Previous organizer. Cinematographic Films. Whole Numbers. Mathematics Teaching. 


\section{INTRODUÇÃO}

O ensino de Matemática, já a algum tempo, tem sido motivo de preocupações tanto para os educandos quanto para os educadores. O ensino de conteúdos de forma descontextualizada, a extensa grade curricular, bem como a pedagogia da transmissão, são algumas das razões que desmotiva os estudantes para o aprendizado da matéria.

A metodologia mais habitual na educação, principalmente no ensino de Matemática acontece, por meio da transmissão de conteúdos, fato este, que leva os alunos a sentirem-se desmotivados, pois se percebe que uma aula expositiva e dialogada nem sempre é suficiente para tornar significativo o conteúdo e alternar metodologias de ensino é necessário para manter o interesse do aluno na disciplina. destacam:

Nesse sentido, Imenes e Lellis (2013, p. 12),

A aula expositiva é a forma de ação pedagógica mais frequentemente adotada pelos professores de Matemática e de outras disciplinas. Essa forma de aula propicia a transmissão rápida e organizada de informações, o que constitui uma vantagem. Entretanto, ela não mobiliza o raciocínio dos alunos, poucos dos quais conseguem se manter atentos durante o desenrolar da aula.

As pesquisas de Freire (2011), ressaltam a importância da dinâmica do ensino da Matemática nas escolas, visto que esta, deve ser significativa e contextualizada, sendo necessário que se encontrem circunstâncias cotidianas para sua aplicação.

Nas palavras de Freire (2011, p. 40):

A escola precisa procurar outros contextos e elaborar atividades significativas para os alunos compreenderem e relacionarem atividades numéricas e simbólicas, encontrando significado nessas atividades e utilizar diversas linguagens matemáticas.

Assim, buscando tornar as aulas de Matemática mais interessantes e significativas, sob a luz da Teoria da Aprendizagem Significativa de David Ausubel, apresentamos neste artigo, uma análise do filme: "Os Delírios de Consumo de Becky Bloom” para ser utilizado como organizador prévio para a introdução do conteúdo dos Números Inteiros.

\section{Números inteiros (z) e suas manifestações}

O estudo dos Números Inteiros sempre foi um obstáculo para os estudantes do $7^{\circ}$ ano do Ensino Fundamental, haja vista, que até o momento, estes não conheciam os números negativos e abstrair a ideia de tirar um número maior de um número menor consiste numa tarefa bastante complexa para esta faixa etária de alunos.

Além disso, ao explicar a regra de sinais para resolver os algoritmos da adição de Números Inteiros, bem como, pedir que os alunos decorem a regra já na introdução do conteúdo, corre-se o risco de a regra ser armazenada de forma arbitrária, fazendo do ensino uma rotina mecânica de aprendizagem.

Nas palavras de Moreira e Masini (1982, p. 8-9):

...] Ausubel define a aprendizagem mecânica (rote learning), como sendo a aprendizagem de novas informações com pouca ou nenhuma associação com conceitos relevantes existentes na estrutura cognitiva. Nesse caso, a nova informação é armazenada de maneira arbitrária.

Em outras palavras, os autores ressaltam que quando o conhecimento é armazenado de forma arbitrária na estrutura cognitiva do indivíduo, ou seja, não realizando nenhuma associação com conceitos já conhecidos pelo estudante, a aprendizagem torna-se mecânica e não significativa para esses indivíduos, o que pode levar ao esquecimento.

Nesse interim, a construção do conceito de Números Inteiros (Z), bem como a realização dos algoritmos da adição e a comparação entre esses números, precisam estabelecer um sentido para os alunos, visto que estes, encontram inúmeras dificuldades, para compreendêlos, pois até o momento conheceram apenas o conjunto dos Números Naturais (N), que é composto somente por números positivos.

De acordo com Teixeira (1993, p. 62):

A construção do conceito de número inteiro, do ponto de vista matemático, é uma ampliação dos naturais, sendo desta perspectiva necessário demonstrar que as leis do sistema de numeração seguem sendo cumpridas...sabemos que na perspectiva histórica ou da evolução do pensamento matemático, tal ampliação encontrou muitas dificuldades e obstáculos".

E ainda, Nascimento (2002, p. 29), sobre a dificuldade de entendimento do conteúdo de Números Inteiros, pelos alunos do $7^{\circ}$ ano, ou $6^{\text {a }}$ série do Ensino Fundamental, tal como da introdução de números negativos também dá sua contribuição:

$\mathrm{Na} 6$ a série do Ensino Fundamental, quando se introduz o conceito de número negativo na escola, os professores começam a perceber que os alunos não realizam corretamente operações de adição e de subtração, em determinadas situações. Muitos deles começam a demonstrar algumas dificuldades [...].

O autor aponta que uma das causas dessas dificuldades apresentadas pelos alunos, nessa fase de escolarização é admitir, a partir de agora, algo menor que zero.

Muitos Matemáticos ao elaborarem o livro didático do $7^{\circ}$ ano, recurso pedagógico bastante utilizado no ensino de Matemática, utilizam-se do conceito de saldos bancários para introduzir o conteúdo de Números Inteiros. Dentre os quais podemos citar: Andrini \& Vasconcellos 
(2013), Ribeiro (2011), Souza \& Pataro (2014), Giovanni Júnior \& Castrucci (2009), entre outros.

No livro didático elaborado por Giovanni Júnior \& Castrucci (2009), encontramos: "Os números positivos e os números negativos aparecem em muitas situações de nosso dia-a-dia: nos saldos bancários, no saldo de gols de uma equipe, na indicação de altitudes ou profundidades, [...]" (2009, p. 32)

E ainda, Imenes e Lellis (2013, p. 121) trazem o seguinte texto em seu material pedagógico:

Os números negativos são também usados nos cálculos de contabilidade necessários no comércio, na indústria e nos bancos. Nesses cálculos, os números negativos indicam despesas (gastos ou dívidas), e os números positivos indicam receitas (recebimentos). Somando uns aos outros, temos o saldo, que pode ser negativo, positivo ou nulo. Um saldo nulo indica que as despesas e as receitas se compensaram.

Neste pensamento, realizar a introdução do conteúdo de Números Inteiros, associando débitos a números negativos e créditos a números positivos, por meio do filme "Os Delírios de Consumo de Becky Bloom" pode tornar significativa e prazerosa a aprendizagem do tema.

\section{Filmes como organizadores prévios}

A priori, considerou-se importante aqui explicitar em que consiste a Teoria da Aprendizagem Significativa, para posteriormente abordar a importância dos organizadores prévios no processo de ensino e aprendizagem.

De acordo com Moreira e Massini (1982, p. 7), a Aprendizagem Significativa pode ser assim descrita:

[...] é um processo pelo qual uma nova informação se relaciona com um aspecto relevante da estrutura de conhecimento do indivíduo. Ou seja, neste processo, a nova informação interage com uma estrutura de conhecimento específica, a qual Ausubel define como conceitos subsunçores ou simplesmente, subsunçores (subsumers), existentes na estrutura cognitiva do indivíduo.

De acordo com os autores, o fator mais importante no processo de aprendizagem é aquilo que o aluno já sabe, pois esse é o ponto de partida para o ensino de novos conceitos.

Sobre os organizadores prévios, Moreira e Massini (1982, p. 11) explicitam: “O uso de organizadores prévios é uma estratégia proposta por Ausubel para deliberadamente, manipular a estrutura cognitiva a fim de facilitar a Aprendizagem Significativa".

Moreira (2012), explicita que um organizador prévio deve partir de conceitos mais gerais conhecidos pelos estudantes para alcançar os conceitos mais específicos a serem ensinados. Assim, um organizador prévio deve servir de ponte cognitiva entre o que o aluno já sabe e o que precisa aprender.

Neste contexto, um organizador prévio pode ser:
(...) um enunciado, um parágrafo, uma pergunta, uma demonstração, um filme, uma simulação e até mesmo uma aula que funcione como pseudo-organizador para toda uma unidade de estudo, ou ainda, um capítulo que se proponha a facilitar a aprendizagem de vários outros em um livro. Não é a forma que importa, mas sim a função dessa estratégia instrucional chamada organizador prévio. (MOREIRA, 2012, p. 10)

Os filmes, neste pensamento, ao serem utilizados como recurso didático-pedagógico, além de ilustrar o conteúdo, podem servir como organizadores prévios, elementos facilitadores da Aprendizagem Significativa.

\section{$O$ filme da proposta}

O filme 'Os delírios de consumo de Becky Bloom', lançado em 10 de abril de 2009, (Censura 10 anos), tem início mostrando a personagem principal, Rebecca Bloomwond (Becky Bloom), quando criança, comprando um sapato de promoção juntamente com sua mãe.

A menina encanta-se com a luxúria dos grandes nomes da moda e ao ver bonitas moças comprando roupas caras e lindas fica imaginando que as mesmas possuíam cartões mágicos para pagar.

O tempo passa e Rebecca torna-se uma moça com sete cartões de crédito. Apesar de trabalhar em uma revista que não era do seu agrado, Becky sempre gasta mais do que ganha. $\mathrm{O}$ susto maior vem quando a revista que a personagem trabalha resolve fechar e Becky fica desempregada e com muitas dívidas para pagar.

Desesperada Becky procura emprego numa revista de moda famosa Alete, mas quando chega percebe que a vaga já foi preenchida. $\mathrm{O}$ informante indica então outra vaga para trabalhar em uma revista de economia, ato que se torna contraditório visto que, a revista dá conselhos sobre controle de finanças e controlar os gastos é justamente o que Becky não sabe fazer.

Depois de ter aceitado o cargo, Becky, fica conhecida como "a menina da echarpe verde", e faz muito sucesso na revista de economia, até que um cobrador desmascara a personagem em público em uma entrevista na TV, explicando que a mesma não cumpre o que diz, e possui inúmeras dívidas bancárias. Novamente Becky perde seu emprego e abalada por tudo o que lhe acontecera, resolve não compactuar mais com as grandes grifes. Neste contexto ela faz um leilão de seus pertences para pagar as dívidas.

\section{Análise do filme na perspectiva da aprendizagem significativa}

Buscando facilitar o ensino dos Números Inteiros para os alunos do $7^{\circ}$ ano, realizamos uma análise do filme "Os Delírios de Consumo de Becky Bloom" e apresentamos alguns recortes que podem servir de ponte cognitiva entre o conhecimento que o aluno já possui e o conteúdo a ser ensinado.

Ressalta-se aqui que inicialmente deve-se proceder uma investigação acerca dos conhecimentos prévios da turma sobre o tema proposto, para que assim, possa-se 
realizar uma análise comparativa dos resultados da didática aplicada.

De acordo com Moreira e Masini (1982, p. 4): Novas ideias e informações podem ser aprendidas e retidas na medida em que conceitos relevantes e inclusivos estejam adequadamente claros e disponíveis na estrutura cognitiva do indivíduo e funcionem, dessa forma, como ponto de ancoragem para as novas ideias e conceitos.

Nesse interim, a cena que se inicia aos 2'22" e termina aos 3' aproximadamente, mostra a personagem adulta, com sete cartões de créditos e muitas dívidas para pagar. Os débitos são excessivamente maiores que os créditos e ao visualizar as faturas, a personagem nem mesmo é capaz de reconhecer os lugares onde entrou para realizar suas compras.

Nesta cena, além de introduzir o conceito dos Números Inteiros, equiparando números positivos a créditos e números negativos a débitos, é possível realizar uma comparação entre débitos e créditos, tornando evidente que a garota possui neste momento um valor negativo de saldos e assim explicitar a comparações de Números Inteiros.

Para Moreira (2008, p. 9):

$\mathrm{Na}$ medida em que o uso de organizadores prévios facilita a Aprendizagem Significativa, a qual, por sua vez, modifica a estrutura cognitiva do aprendiz, tornando-a mais capaz de assimilar e reter informações subsequentes, professores e especialistas deveriam procurar utilizar esta estratégia ao prepararem aulas e texto didáticos.

Buscando também, aclarar os alunos acerca da importância do controle financeiro, bem como do equilíbrio que deve existir entre débitos e créditos, nas cenas que seguem, pode-se perceber o "poder de persuasão" que as lojas de grandes grifes exercem sobre os jovens, visto que embora a personagem tentasse se convencer de que não precisava comprar a echarpe verde, a beleza esplendorosa suspensa no manequim não deixava a moça ir embora, cena que se inicia aos 4'13" e termina aos 5'33'. Nesta cena, é relevante discutir a importância de não se deixar dominar pelo poder esplendoroso das grandes grifes para se ter um real controle dos gastos.

De acordo com Moreira e Masini (1982, p. 42):

É importante selecionar as ideias básicas, para não sobrecarregar o aluno de informações desnecessárias, dificultando a aquisição de uma estrutura cognitiva adequada. A coordenação e integração do assunto em diferentes níveis também é importante.

Entre os 28'30" e 30' aproximadamente de filme, é possível perceber que a personagem está ficando enlouquecida com a insistência dos cobradores, consequência da má administração financeira, visto que a mesma possui um valor negativo de saldo, bem distante dos valores positivos necessários para quitar suas dívidas.
Nesta cena, é relevante expor um modelo de extrato bancário aos alunos e com eles resolver as adições necessárias de Números Inteiros demonstrando saldos negativos e positivos. É possível também trabalhar com os valores que o próprio filme explicita.

Neste contexto, além de introduzir o Conjunto dos Números Inteiros, com este tipo de organizador prévio é possível conscientizar os alunos desde cedo, da importância de saber administrar seus gastos e valorizar o dinheiro dos pais, adquirindo somente o que realmente é necessário no seu dia-a-dia.

O excesso e a compulsividade por comprar tudo o que se quer, pode trazer sérias consequências e dívidas que podem perdurar por anos e anos.

Ao findar a apresentação do organizador prévio, é necessário realizar uma nova coleta de dados, para verificar se o organizador prévio serviu de ponte cognitiva para a introdução de Números Inteiros e passa-se então para uma abordagem mais específica acerca do conteúdo.

\section{CONSIDERAÇÕES FINAIS}

Ao realizar a pesquisa, concluiu-se que, sendo o conteúdo de Números Inteiros, um conteúdo de difícil entendimento para os alunos de $7^{\circ}$ ano, conforme pudemos fundamentar anteriormente, cabe ao professor educador buscar estratégias de ensino que possam facilitar a aprendizagem do tema.

Desta forma, acredita-se que unir o útil ao agradável, utilizando o filme "Os Delírios de Consumo de Becky Bloom” para introduzir o conceito de números Inteiros, bem como ensinar o algoritmo da adição destes números por meio do filme, podem tornar o aprendizado do tema mais divertido e motivador aos olhos destes aprendizes.

Neste pensamento, ao utilizar um filme como organizador prévio para o ensino de Matemática, não é necessário que este explicite em seu roteiro, uma fórmula Matemática, ou uma equação do tema que se deseja ensinar, ao contrário, os organizadores prévios são considerados materiais instrucionais para serem apresentados antes do conteúdo específico a ser ensinado, partindo portanto, do conhecimento que o aluno já possui e servindo de ponte cognitiva para a introdução do conteúdo específico, objetivo da aula.

Nesta perspectiva acredita-se que o filme: "Delírios de Consumo de Becky Bloom" pode contribuir com a aprendizagem significativa do Conteúdo de Números Inteiros.

\section{REFERÊNCIAS}

ANDRINI, A.; VASCONCELlOS, M. J. Praticando Matemática. $7^{\circ}$ ano. $3^{\text {a }}$ edição. São Paulo. Editora do Brasil, 2013.

FREIRE, R. S. Desenvolvimento de conceitos algébricos por professores dos anos iniciais do Ensino Fundamental. Fortaleza, 180 p., 2011. Tese (Doutorado em Educação) Universidade Federal do Ceará. 
GIOVANNI, J. J. R; CASTRUCCI, B. A Conquista da Matemática. $7^{\circ}$ ano. Manual do professor. $1^{\mathrm{a}}$ edição. São Paulo. FTD, 2009.

IMENES, L. M.; LELLIS, M. Matemática: Imenes \& Lellis. $7^{\circ}$ ano. Manual do professor. São Paulo. Editora Moderna, 2012.

MOREIRA, M. A. Organizadores prévios e Aprendizagem Significativa. Revista Chilena de Educación Científica, vol. 7, nº 2, p. 23-30, 2008.

MOREIRA, M. A. Aprendizagem Significativa: a teoria e textos complementares. São Paulo: Livraria da Física, 2012.

MOREIRA, M. A.; MASINI, E. F. S. Aprendizagem Significativa: a teoria de David Ausubel. São Paulo: Moraes, 1982.

NASCIMENTO, R. A. Um Estudo Sobre Obstáculos em Adição e Subtração de Números Inteiros Relativos: Explorando a reta numérica dinâmica.. Recife: Universidade Federal de Pernambuco, Tese de Mestrado apresentada ao Departamento de Educação, 2002.

RIBEIRO, J. Projeto Radix: Matemática $7^{\circ}$ ano. Manual do professor. Brasília/DF. Editora Scipione, 2011.

SOUZA, J.; PATARO, P. M. Vontade de saber Matemática. $7^{\circ}$ ano. Manual do professor. São Paulo. Editora FTD. 2014.

TEIXEIRA, L. R. M. Aprendizagem Operatória de números inteiros: obstáculos e dificuldades. Revista PróPosições, vol. 4, nº 1[10], UNICAMP. Março, 1993. 